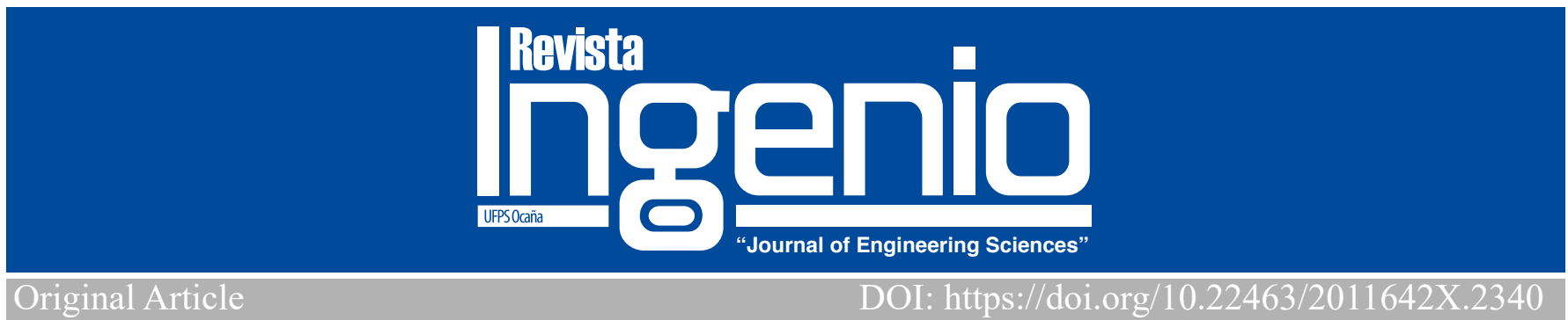

\title{
A review of working fluid mixtures for low temperature power cycles and their thermodynamic modeling
}

Una revisión de fluidos de trabajo de tipo mezclas para ciclos de potencia de baja temperatura y su modelado termodinámico

\section{PhD. Carlos Javier Noriega-Sánchez ${ }^{1}$}

${ }^{1}$ Grupo de Investigación en Tecnologia y Desarrollo de Ingenierías GITYD, Universidad Francisco de Paula Santander seccional Ocaña, Colombia, Orcid:https://orcid.org/0000-0002-7782-8119, Email: cjnoriegas@ufpso.edu.co

How to cite: C. J. Noriega, “A review of working fluid mixtures for low temperature power cycles and their thermodynamic modeling”, Revista Ingenio, 18(1),pp. 62-69, 2021

Received date: 21 de julio de 2020 Approval date: 10 de noviembre de 2020

\section{ABSTRACT}

Key words:

This paper summarizes a bibliographic review of the main articles published in recent years in the power cycles area, with special emphasis on working fluid mixtures. Likewise, the most relevant theoretical fundaments for performing the mathematical modeling

State equation, power cycle, organic fluids, of this class of working fluids and, therefore, obtaining their thermodynamic properties, as well as the experimental methods used in mixtures. the characterization of the phase equilibrium that allow obtaining the adjustment parameters are covered in this article.

\section{RESUMEN}

Palabras claves:

Este trabajo condensa una revisión bibliográfica de los principales trabajos publicados en los últimos años en el área de ciclos de potencia, con especial énfasis en los fluidos de trabajo de tipo mezclas. Así mismo, los fundamentos teóricos más relevantes para realizar el modelado matemático de esta clase de fluidos de trabajo y, por ende, obtener sus propiedades termodinámicas, así como

Ecuación de estado, ciclo de potencia, fluidos orgánicos, mezclas. los métodos experimentales usados en la caracterización del equilibrio de las fases que permiten la obtención de los parámetros de ajuste, también son abordados en este artículo.

\section{Introduction}

Due to the growth of the world's population and the increase in per capita energy consumption, it is not surprising that there is an imbalance between the capacity to generate energy and environmental care. Humanity needs large amounts and diverse forms of energy, this trend can be seen in Figure 1. As presented, over a period of 46 years, energy consumption by economic sectors in the world increased by $44 \%$. Most of this energy resource comes from non-renewable sources [1], resulting in increased pollutant and greenhouse gas emissions such as carbon dioxide $\left(\mathrm{CO}_{2}\right)$.

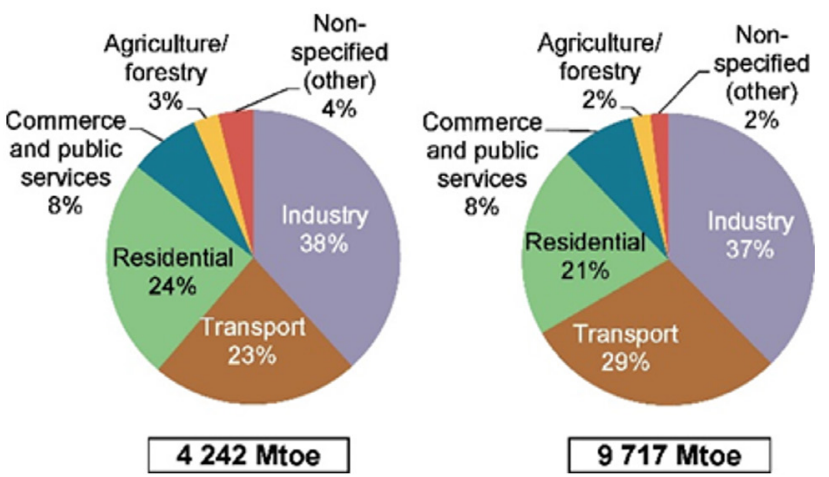

Figure 1. Total energy consumption by economic sector in the world in 1971 and 2017 (Mtoe: Millions of tonnes of oil equivalent). Source. [1]. 
The Colombian situation is somewhat different from the world scenario, given that the national energy mix is strongly influenced by hydroelectric sources. However, the data for 2020 shows that the electricity supplied to the national energy mix from non-renewable sources represents $25.1 \%$ of the total. That is to say, approximately $1210 \mathrm{MWh}$ of the installed capacity - thermal sources are comprised of: coal, natural gas, biomass, and diesel-[2].

Bearing this in mind, it is evident the importance of studying and optimizing the processes to obtain energy, such as the power cycles widely used in thermoelectric plants, especially in low temperature heat sources $\left(<316^{\circ} \mathrm{C}\right)$, given that this is a large energy source [3-4]. In this sense, $\mathrm{CO}_{2}$ emerges not only as a villain, but as a possible ally, mainly due to the particular behavior of its thermophysical properties, especially its specific heat at constant pressure $(\mathrm{Cp})$, in regions close to the critical ones that can translate into considerable efficiency gains [5].

However, its low critical temperature $\left(30.98^{\circ} \mathrm{C}\right)$ imposes restrictions on the condensation process when used in the Rankine cycles [6], as it requires the temperature of the cooling fluid (air or water) to be very low $\left(<25^{\circ} \mathrm{C}\right)$, which is a limitation in tropical regions. On the other hand, the high operating pressures of $\mathrm{CO}_{2}$ in such cycles $(6-16 \mathrm{MPa})$ pose challenges for system design [7]. In view of this limitation, mixtures of organic fluids, especially with $\mathrm{CO}_{2}$, appear as an alternative through which new working fluids for Organic Rankine Cycles (ORCs) can be considered. The mixtures provide numerous options for obtaining optimal working fluids in power cycles, for a given set of equipment and operating conditions [8].

Given the above, this paper describes a comprehensive literature review on power cycles using binary mixtures as working fluids, either between two organic fluids or between an organic fluid and $\mathrm{CO}_{2}$. The paper begins with historical and technical background, mathematical modeling to obtain their thermodynamic properties and finally, a review of experimental methods through which the adjustment parameters for mathematical modeling can be obtained. Although the temperatures at which low-temperature sources operate are not the most favorable operating range for $\mathrm{CO}_{2}$, since traditional organic fluids have proven to be more efficient in most of these applications [9], $\mathrm{CO}_{2}$ remains attractive because of the added environmental value, especially when several organic fluids are being discontinued for applications in power cycles depending on environmental constraints [10].

The document is divided into sections. Section 2 describes the methodology used and sections 3 to 6 present the results of the study as follows: section 3 presents the most relevant work in the area of ORC with low temperature sources using binary mixtures of organic fluids as working fluids. Section 4 summarizes the advantages of using $\mathrm{CO}_{2}$ in power cycles powered by waste heat. Subsequently, the concepts of thermodynamic modeling of mixtures are pointed out in section 5. Finally, the experimental methods of vapor-liquid phase equilibrium with mixtures of $\mathrm{CO}_{2}$ and organic fluids of the refrigerant type, necessary to identify the parameters of adjustment of equations of state for mixtures, are summarized. It is worth noting that the analysis of the information collected is done at the end of each section.

\section{Methodology}

The advanced search functionality of the ScienceDirect platform was used to locate the bibliographic references [11]. The terms used were: power cycles, organic fluids, organic fluid mixtures, and liquid-vapor phase equilibrium with $\mathrm{CO}_{2}$ mixtures. According to the subject of the review, only the articles published in the last decade were considered, which allowed having a base of articles that oscillated between 85 and 130 records. The most relevant and most frequently cited publications were finally selected in the present work. It is important to note that ScienceDirect is a website that allows access to a large database of scientific research and groups together a large number of journals in the fields of physical and engineering sciences. These journals are used for this review article.

\section{ORC working-fluid mixtures}

The working fluid is among the most relevant variables when developing an ORC project. [12-13]. This variable are essential for these systems to make proper use of the available heat source, operate with high efficiency, and allow the economic viability of the installation [14]. The relevance of the working fluid is, in fact, closely related to its thermophysical properties. For example, the thermal conductivity of the fluid impacts the heat transfer coefficient of heat exchangers. The viscosity and density of the fluid influence the pressure drops in the system, and therefore the size of the heat exchangers and the turbine. Other no less important aspects are related to the toxicity and flammability, cost, availability and environmental safety given by the GWP (global warming potential) and ODP (ozone depletion potential) [15].

Several papers in the power cycle literature have focused on identifying promising pure fluids in ORC applications. However, it is clear that several promising fluids still have limitations in the environmental issue mainly due to their GWP value. On the other hand, these fluids are not suitable for sensible heat sources such as waste heat because their phase change occurs at constant temperatures [16-17-18].

During the phase change process (liquid-vapor), a zeotropic mixture has a variable temperature [18]. This feature can be used to produce a better correspondence 
between the temperature profiles, between the mixture and the heat transfer fluid in the condensation stage and/or in the evaporation stage and, therefore, the irreversibilities of the system can be minimized [19]. Another advantage of working fluids mixtures is that they can acquire thermodynamic properties similar to those of their pure constituents, by combining the fractions of the components. The impact of zeotropic mixtures on a Rankine cycle can be observed in the work of Chys et al. [20]. In this study, the authors evaluated the heat recovery potential of 12 pure organic fluids, as well as their binary and ternary mixtures, considering two temperatures of the heat source $\left(150^{\circ} \mathrm{C}\right.$ and $250^{\circ} \mathrm{C}$ ). In the analysis, the authors determined the optimal concentration to produce maximum power without risk of mixture fractionation. The results showed that the zeotropic mixtures had a positive effect on the system's performance, improving up to $20 \%$ the generation of electrical energy with a $150{ }^{\circ} \mathrm{C}$ source. This increase was less pronounced with a $250^{\circ} \mathrm{C}$ source. The authors concluded that the inclusion of a third component in the mixture has small impacts on system performance parameters, (Figure 2).

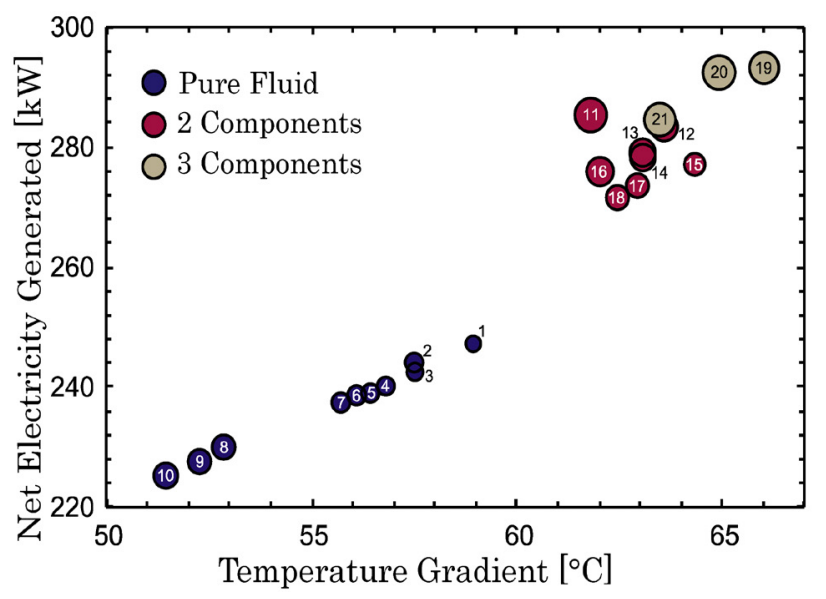

Figure 2. Maximum electrical power generated depending on the temperature gradient of the heat source. The size of the circle in the figure is proportional to the efficiency of the system. Source: [20].

Multi-objective optimization studies were also performed by [21-22] considering binary mixtures as working fluids in ORC. The results showed that blends exhibit an improvement over pure fluids, but are also associated with higher costs.

In general, the works with organic fluid mixtures in ORC show the potential for improvement in the performance parameters of the system. However, a large number of these fluids still do not present solutions in terms of flammability, toxicity, and environmental aspects. These problems have been addressed in several studies through $\mathrm{CO}_{2}$ mixtures. In general, such mixtures have shown a suppression of hydrocarbon flammability when the $\mathrm{CO}_{2}$ ratio exceeds $30 \%$
[23]. In addition, the GWP value decreases as $\mathrm{CO}_{2}$ in the mixture increases [24-25]. Therefore, it can be observed that, in addition to overcoming environmental and safety limitations, $\mathrm{CO}_{2}$ mixtures provide acceptable performance parameters [26-27].

\section{4. $\mathrm{CO}_{2}$ mixtures in Rankine power cycles}

Few papers have been published in the literature on $\mathrm{CO}_{2}$ and organic fluid mixtures for Rankine cycles. For example, the suppression of hydrocarbon flammability in $\mathrm{CO}_{2}$ mixtures with a mass fraction of $30 \% \mathrm{CO}_{2}$, as well as their performance in a Rankine cycle was evaluated by [28]. In the analyses, the authors considered irreversibilities in the components, pressure drops, and pinch point values of 5 and $10{ }^{\circ} \mathrm{C}$ in the recuperator and heat exchangers, respectively. The condensation temperature was $30^{\circ} \mathrm{C}$, and $300^{\circ} \mathrm{C}$ for the sensible heat source. The results showed that the mixtures of $\mathrm{CO}_{2}$ and isopentane show a high irreversibility, mainly in the recuperator. However, the efficiency of the cycle showed considerable improvements with the mixture of $\mathrm{CO}_{2}$ and propane $(15-8 \%)$. Mixtures of sulfur hexafluoride (SF6) and $\mathrm{CO}_{2}$ were also studied by [29]. This work aimed to determine the impact of SF6 concentrations in the mixture on the size of the components (heat exchange area), heat transfer coefficients, and cycle efficiency assuming a geothermal heat source at $160{ }^{\circ} \mathrm{C}$. The authors showed that, under the modeled conditions, a mole fraction of $20 \%$ SF6 produced the highest cycle efficiency (15\%).

A qualitative analysis considering zeotropic $\mathrm{CO}_{2}$ mixtures with various refrigerants, particularly HFCs (HydroFluoroCarbons), was carried out by [25]. In that study, it was assumed that the cycle operated in a transcritical condition, and temperatures of 150 and $12{ }^{\circ} \mathrm{C}$ were assumed for the sensible heat source and the cooling fluid, respectively. The properties in the different points of the system were obtained from the Reference Fluid Thermodynamic and Transport Properties Database (REFPROP) of the National Institute of Standards and Technology. In the results, the authors emphasize the advantages of the mixtures in terms of their environmental aspects (flammability, GWP, and toxicity), and the mixtures of $\mathrm{CO}_{2} / \mathrm{R}-161, \mathrm{CO}_{2} / \mathrm{R}-1234 \mathrm{ze}$ and $\mathrm{CO}_{2} / \mathrm{R}-1234 \mathrm{yf}$ stand out as suitable working fluids for waste heat recovery systems. A Rankine cycle similar to that of the reference [25], but with a $\mathrm{CO}_{2} /$ Propane mixture was studied by [30]. The optimal values of net power and cycle efficiency, for various supercritical pressures in the high temperature heat exchanger (in which heat is added to the working fluid), were presented.

Noriega et al. [5] presented the performance of $\mathrm{CO}_{2} /$ refrigerant mixtures in a Rankine cycle in which the working fluid is at a higher pressure than its critical pressure, and it is in the condition in which the heat recovery process from 
the heat source takes place - This type of cycle is known in the literature as a transcritical cycle. The effects of mixture composition, turbine inlet pressure, and heat source temperature on cycle performance were addressed, and it was concluded that the cycle operating with larger mass fractions of refrigerant exceeds the cycle performance with near pure $\mathrm{CO}_{2}$.

Recently, Xia et al. [27] studied binary organic fluid mixtures with $\mathrm{CO}_{2}$ to overcome the problem of condensation at high critical temperatures. Single and multiple objective optimizations were performed to achieve the best system performance. The results show that transcritical power cycles using binary mixtures with $\mathrm{CO}_{2}$ could obtain better thermodynamic and exergo-economic performances compared to those using pure $\mathrm{CO}_{2}$ for low and high temperature heat sources.

The above analyses are theoretical, therefore, the thermodynamic properties of these mixtures are based on data from literature-validated and widely accepted property packages [31-32]. However, certain precautions should be taken when the adjustment parameters of these mixtures are not experimentally validated, as the properties are estimates and therefore the results may be compromised. Therefore, the following section presents the different models and experimental approaches available in the literature for the treatment of mixtures and obtaining the adjustment parameters, in particular those with $\mathrm{CO}_{2}$.

\section{Thermodynamic modeling of mixtures}

Knowledge of high-pressure equilibrium data is vital to understanding and optimizing countless processes. To search for such information, the experimental approach requires high costs and time. Bearing this in mind, a wide variety of alternative approaches have been developed, ranging from empirical or semi-empirical correlations to molecular models based on statistical mechanics, from which it is possible to predict the phase equilibrium and, consequently, reduce the amount of experimental work [33].

\subsection{Cubic Equations of State}

Any equation that relates the temperature, pressure, and specific volume of a substance is called the Equation of State (EOS). When the substance is constituted by a mixture of $n$ components, it is necessary to know the fraction ( $\mathrm{x}$ ) of $\mathrm{n}-1$ components to be considered in the EOS of the mixture Note that the sum of the fractions of the different components of a mixture is always equal to the unit.

The first EOS with molecular foundations was proposed by Van der Waals in 1873. Despite its limited accuracy, it was the first cubic equation capable of representing the coexistence of the liquid and vapor phases [34]. The qualitative success of the Van de Waals equation to describe the liquid and vapor phases and their transition, including the critical point, encouraged the development of improved EOS, such as Peng-Robinson EOS [35]. The Peng-Robinson EOS in terms of the compressibility factor and the expressions for the parameters a (attractive forces between molecules) and $\mathrm{b}$ (volume occupied by the molecules) are presented from Equation (1) to Equation (5):

$$
\begin{gathered}
\mathrm{Z}=\frac{\mathrm{V}}{\mathrm{V}-b}-\frac{a(\mathrm{~T})}{\mathrm{RT}[\mathrm{V}(\mathrm{V}+b)+b(\mathrm{~V}-b)]} \\
a(\mathrm{~T})=0.45724 \frac{\mathrm{R}^{2} \mathrm{~T}_{\text {Crit }}^{2}}{\mathrm{P}_{\text {Crit }}^{2}} \Omega \\
\Omega=\left\{1+k\left[1-\left(\frac{\mathrm{T}}{\mathrm{T}_{\text {Crit }}}\right)^{0.5}\right]\right\}^{2} \\
k=0.37464+1.5422 \omega-0.26922 \omega^{2} \\
b=0.0778 \frac{\mathrm{RT}_{\text {Crit }}}{\mathrm{P}_{\text {Crit }}}
\end{gathered}
$$

where $\mathrm{Z}$ is the compressibility factor, $\mathrm{T}$ the temperature, $\mathrm{V}$ the molar volume, $R$ the universal gas constant, $\omega$ the acentric factor, Tcrit and Pcrit are the critical fluid temperature and pressure, respectively. Due to its simplicity and robustness in relation to the large number of existing databases, the Peng-Robinson equation is one of the most widely used EOS in the industry. This equation works well with nonpolar molecules such as light hydrocarbons or in mixtures such as those contained in natural gas. Reasonable results can also be found in more complex systems, and even for polar molecules, but not for systems that have some kind of molecular association, for example, hydrogen bonds [36].

\subsection{Activity Coefficient Models}

One method that seeks to circumvent the behavior of strongly non-ideal mixtures (i.e. with strong molecular associations or highly polar fluids) is to estimate the fugacity of the components in the liquid phase using an Excess Gibbs Energy (GE) or an activity coefficient model $(\gamma)$ [37].

In general, the purpose of activity coefficient models is to represent these coefficients as a function of temperature and composition at constant pressure. Several of these models take the form of empirical expressions containing a set of parameters that can be obtained by adjusting the experimental VLE (vapor-liquid equilibrium) data of the mixture. 


\subsection{Incorporation of activity coefficient models into equations of state}

The limitation of the EOS in the case of mixtures with strongly non-ideal behavior can also be mitigated by choosing a suitable mixing rule. An attractive way to combine them is to incorporate an activity coefficient model in the mixing rule used in the EOS. The aim of this approach is to determine the $a$ and $b$ parameters of the EOS by matching the excess Gibbs energy predicted by the EOS with that given by an activity coefficient model, that is,

$$
\mathrm{G}^{\mathrm{E}}(\mathrm{P}, \mathrm{T}, x)=\mathrm{A}_{\infty}^{\mathrm{E}}
$$

where $\left(A_{\infty}^{\mathrm{E}}\right)$ is the excess Helmholtz free energy at infinite pressure that is obtained through an activity coefficient model. [38].

\section{Experimental methods for high-pressure phase equilibrium}

Different experimental techniques to determine phase balance at high pressures are presented and discussed in the literature [39-41-42]. As shown in Figure 3, these methods can be classified into two groups: analytical and synthetic methods. The analytical method allows sampling of the equilibrium phases for analysis. Although this implies a complication for the experimental apparatus, additional advantages, such as the possibility of investigating multiphase systems, make this method widely used [43-44-45].

Unlike the analytical method, the synthetic method seeks to observe the behavior of the phases in an equilibrium chamber of a mixture whose general composition is precisely known. The pressure and temperature conditions are pre-set, resulting in a homogeneous solution. As sampling is not necessary, synthetic methods can be applied in situations where analytical methods fail; for example, in the vicinity of the critical point, where phase separation is difficult due to the similarity of the coexisting phase densities [46-47-48-49-50]

\section{Analitical methods}
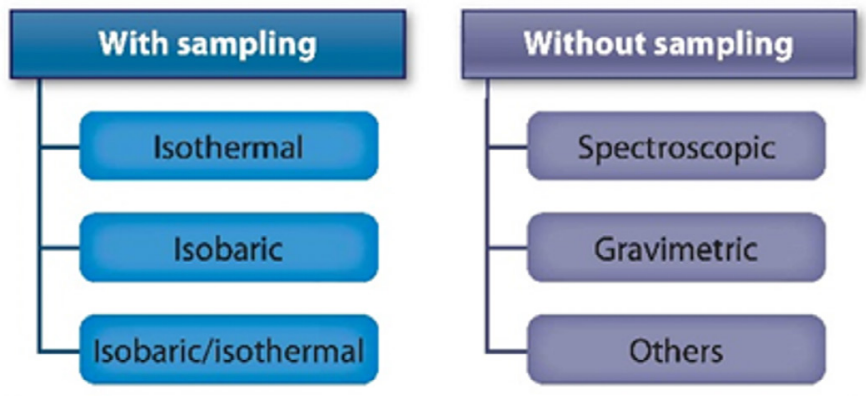

\section{Synthetic methods}

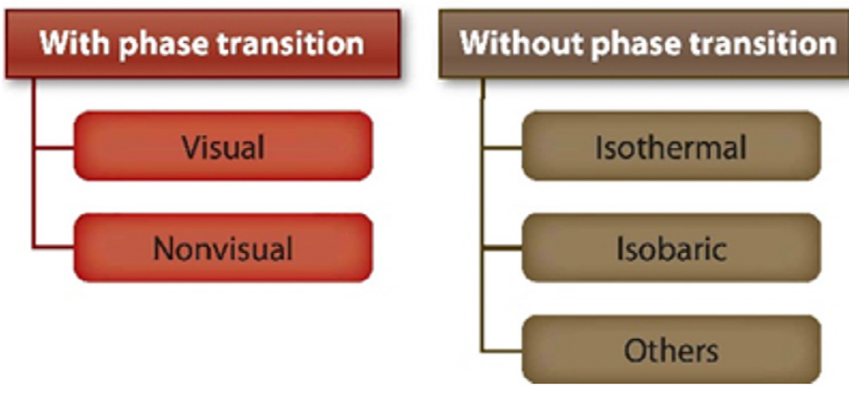

Figure 3. Classification of experimental methods for highpressure phase equilibrium. Source: [40].

\section{Conclusions}

This literature review shows much of what has already been developed with respect to the use of organic and $\mathrm{CO}_{2}$ mixtures as working fluids in Rankine power cycles, focusing on lowtemperature heat recovery. In view of the above, the qualities of the mixtures for this type of application become evident; therefore, they are an appropriate option to be used in the exploitation of this type of sources. The different approaches of EOS to calculate and model the phase equilibrium, as well as the experimental techniques to obtain equilibrium data, were also studied.

In general, the works reviewed show that hydrocarbons and organic refrigerants have desirable thermodynamic properties for use in Rankine power cycles. However, they exhibit some risk of flammability and/or environmental disadvantages (high GWP) when used pure in this kind of cycles. On the other hand, working fluid mixtures can overcome the above limitations when high fractions of nonflammable fluids with low GWP values (such as $\mathrm{CO}_{2}$ ) are incorporated among their components.

The different studies related to working fluid mixtures indicate that there is a need for more complete studies in which the optimization of the components of the mixture is incorporated in the analyses, so that all possible combinations can be evaluated and an optimal solution can be determined.

The Peng-Robinson cubic equation of state stands out for being the most cited EOS model in the literature for modeling pure fluids and mixtures. The accuracy of this equation ends up being limited to correlate equilibrium data of molecules with high molecular complexity or with strong molecular interactions. However, its predictive capacity can be improved when activity coefficient models are incorporated into the mixing rules, especially in the case of fluids that exhibit highly non-ideal behavior. 
A detailed understanding of the different experimental methods is essential for choosing the most suitable method for a given measurement task, since there is a wide spectrum of methods and therefore each technique has advantages and disadvantages.

\section{References}

[1] IEA, "World energy balances: overview." IEA, 2018.

[2] Acolgen - Asociación Colombiana de Generadores de Energía Eléctrica, [Online]. Available: https://www.acolgen.org.co/"'.

[3] DOE, "Waste Heat Recovery: Technology and Opportunities in U.S. Industry." 2008, [Online]. Available: U.S Department of Energy.

[4] A. Mahmoudi, M. Fazli, and M. R. Morad, "A recent review of waste heat recovery by Organic Rankine Cycle," Applied Thermal Engineering, vol. 143, pp. 660-675, Oct. 2018.

[5] C. J. N. Sánchez and A. K. da Silva, "Technical and environmental analysis of transcritical Rankine cycles operating with numerous $\mathrm{CO} 2 \mathrm{mix}-$ tures," Energy, vol. 142, pp. 180-190, Jan. 2018.

[6] B. F. Tchanche, Gr. Lambrinos, A. Frangoudakis, and G. Papadakis, "Low-grade heat conversion into power using organic Rankine cycles - A review of various applications," Renewable and Sustainable Energy Reviews, vol. 15, no. 8, pp. 3963-3979, Oct. 2011.

[7] L. A. de Araujo Passos, S. L. de Abreu, and A. K. da Silva, "Optimal scale of solar-trough powered plants operating with carbon dioxide," Applied Thermal Engineering, vol. 124, pp. 1203-1212, Sep. 2017.

[8] A. Modi and F. Haglind, "A review of recent research on the use of zeotropic mixtures in power generation systems," Energy Conversion and Management, vol. 138, pp. 603-626, Apr. 2017.

[9] V. L. Le, M. Feidt, A. Kheiri, and S. Pelloux-Prayer, "Performance optimization of low-temperature power generation by supercritical ORCs (organic Rankine cycles) using low GWP (global warming potential) working fluids," Energy, vol. 67, pp. 513-526, Apr. 2014.

[10] I. Sarbu, "A review on substitution strategy of non-ecological refrigerants from vapour compression-based refrigeration, air-conditioning and heat pump systems," International Journal of Refrigeration, vol. 46, pp. 123-141, Oct. 2014.

[11] ScienceDirect.com $\mid$ Science, health and medical journals, full text articles and books. [Online]. Available: https://www.sciencedirect.com/"'.

[12] H. Chen, D. Y. Goswami, and E. K. Stefanakos,
"A review of thermodynamic cycles and working fluids for the conversion of low-grade heat," Renewable and Sustainable Energy Reviews, vol. 14, no. 9, pp. 3059-3067, Dec. 2010.

[13] C. J. Noriega Sanchez, L. Gosselin, and A. K. da Silva, "Designed binary mixtures for subcritical organic Rankine cycles based on multiobjective optimization," Energy Conversion and Management, vol. 156, pp. 585-596, Jan. 2018.

[14] B. Tchanche, S. Quoilin, S. Declaye, G. Papadakis, and V. Lemort, "Economic Optimization of Small Scale Organic Rankine Cycles,” Jun. 2010.

[15] J. Bao and L. Zhao, "A review of working fluid and expander selections for organic Rankine cycle," Renewable and Sustainable Energy Reviews, vol. 24, pp. 325-342, Aug. 2013.

[16] J. L. Wang, L. Zhao, and X. D. Wang, "A comparative study of pure and zeotropic mixtures in low-temperature solar Rankine cycle," Applied Energy, vol. 87, no. 11, pp. 3366-3373, Nov. 2010.

[17] M. Chys, M. van den Broek, B. Vanslambrouck, and M. De Paepe, "Potential of zeotropic mixtures as working fluids in organic Rankine cycles," Energy, vol. 44, no. 1, pp. 623-632, Aug. 2012.

[18] D. Luo, A. Mahmoud, and F. Cogswell, "Evaluation of Low-GWP fluids for power generation with Organic Rankine Cycle," Energy, vol. 85, pp. 481-488, Jun. 2015.

[19] K. Braimakis, M. Preißinger, D. Brüggemann, S. Karellas, and K. Panopoulos, "Low grade waste heat recovery with subcritical and supercritical Organic Rankine Cycle based on natural refrigerants and their binary mixtures," Energy, vol. 88, pp. 80-92, Aug. 2015.

[20] M. Sadeghi, A. Nemati, A. ghavimi, and M. Yari, "Thermodynamic analysis and multi-objective optimization of various ORC (organic Rankine cycle) configurations using zeotropic mixtures," Energy, vol. 109, pp. 791-802, Aug. 2016.

[21] Y. Feng, T. Hung, K. Greg, Y. Zhang, B. Li, and J. Yang, "Thermoeconomic comparison between pure and mixture working fluids of organic Rankine cycles (ORCs) for low temperature waste heat recovery," Energy Conversion and Management, vol. 106, pp. 859-872, Dec. 2015.

[22] O. A. Oyewunmi and C. N. Markides, "Thermo-Economic and Heat Transfer Optimization of Working-Fluid Mixtures in a Low-Temperature Organic Rankine Cycle System," Energies, vol. 9, no. 6, p. 448, Jun. 2016.

[23] M. G. Zabetakis, Flammability characteristics of combustible gases and vapors. Washington DC: 
US Dept. of the Interior, 1965.

[24] H. M. M. Afroz and A. Miyara, "Binary mixtures of carbon dioxide and dimethyl ether as alternative refrigerants and their vapor-liquid equilibrium data predicti," International Journal of Engineering, Science and Technology, vol. 3, no. 1, 2011.

[25] B. Dai, M. Li, and Y. Ma, "Thermodynamic analysis of carbon dioxide blends with low GWP (global warming potential) working fluids-based transcritical Rankine cycles for low-grade heat energy recovery," Energy, vol. 64, pp. 942-952, Jan. 2014.

[26] G. Shu, Z. Yu, H. Tian, P. Liu, and Z. Xu, "Potential of the transcritical Rankine cycle using CO2based binary zeotropic mixtures for engine's waste heat recovery," Energy Conversion and Management, vol. 174, pp. 668-685, Oct. 2018.

[27] J. Xia, J. Wang, G. Zhang, J. Lou, P. Zhao, and Y. Dai, "Thermo-economic analysis and comparative study of transcritical power cycles using CO2-based mixtures as working fluids," Applied Thermal Engineering, vol. 144, pp. 31-44, Nov. 2018.

[28] P. Garg, P. Kumar, K. Srinivasan, and P. Dutta, "Evaluation of carbon dioxide blends with isopentane and propane as working fluids for organic Rankine cycles," Applied Thermal Engineering, vol. 52, no. 2, pp. 439-448, Apr. 2013.

[29] H. Yin, A. S. Sabau, J. C. Conklin, J. McFarlane, and A. L. Qualls, "Mixtures of SF6-CO2 as working fluids for geothermal power plants," Applied Energy, vol. 106, pp. 243-253, Jun. 2013.

[30] L. Pan, X. Wei, and W. Shi, "Performance analysis of a zeotropic mixture (R290/CO2) for trans-critical power cycle," Chinese Journal of Chemical Engineering, vol. 23, no. 3, pp. 572577, Mar. 2015.

[31] O. Kunz and W. Wagner, "The GERG-2008 Wide-Range Equation of State for Natural Gases and Other Mixtures: An Expansion of GERG2004," J. Chem. Eng. Data, vol. 57, no. 11, pp. 3032-3091, Nov. 2012.

[32] NIST, REFPROP Version 9.1. 2013.

[33] J. M. SMITH, H. C. V. NESS, and M. M. ABBOTT, Introdução à termodinâmica da engenharia química, vol. 1. Rio de Janeiro: LTC, 2013.

[34] Y. S. Wei and R. J. Sadus, "Equations of state for the calculation of fluid-phase equilibria," AIChE Journal, vol. 46, no. 1, pp. 169-196, 2000.

[35] D.-Y. Peng and D. B. Robinson, "A New Two-Constant Equation of State," Ind. Eng. Chem. Fund., vol. 15, no. 1, pp. 59-64, Feb.
1976.

[36] A. Anderko, "4 Cubic and generalized van der waals equations," in Experimental Thermodynamics, vol. 5, J. V. Sengers, R. F. Kayser, C. J. Peters, and H. J. White, Eds. Elsevier, 2000, pp. 75-126.

[37] M. D. Koretsky, Engineering and Chemical Thermodynamics. USA: Willey, 2013.

[38] D. S. H. Wong and S. I. Sandler, "A theoretically correct mixing rule for cubic equations of state," AIChE Journal, vol. 38, no. 5, pp. 671-680, 1992.

[39] R. Dohrn and G. Brunner, "High-pressure fluid-phase equilibria: Experimental methods and systems investigated (1988-1993)," Fluid Phase Equilibria, vol. 106, no. 1, pp. 213-282, May 1995.

[40] M. Christov and R. Dohrn, "High-pressure fluid phase equilibria: Experimental methods and systems investigated (1994-1999)," Fluid Phase Equilibria, vol. 202, no. 1, pp. 153-218, Oct. 2002.

[41] R. Dohrn, S. Peper, and J. M. S. Fonseca, "High-pressure fluid-phase equilibria: Experimental methods and systems investigated (20002004)," Fluid Phase Equilibria, vol. 288, no. 1, pp. 1-54, Jan. 2010.

[42] R. Dohrn, J. M. S. Fonseca, and S. Peper, "Experimental Methods for Phase Equilibria at High Pressures," Annual Review of Chemical and Biomolecular Engineering, vol. 3, no. 1, pp. 343367, 2012.

[43] J. S. Lim, J. M. Jin, and K.-P. Yoo, "VLE measurement for binary systems ofCO2+1,1,1,2-tetrafluoroethane (HFC-134a) at high pressures," The Journal of Supercritical Fluids, vol. 44, no. 3, pp. 279-283, Apr. 2008.

[44] G. Di Nicola, C. Di Nicola, A. Arteconi, and R. Stryjek, "PVTx Measurements of the Carbon Dioxide + 2,3,3,3-Tetrafluoroprop-1-ene Binary System," J. Chem. Eng. Data, vol. 57, no. 2, pp. 450-455, Feb. 2012.

[45] N. Juntarachat, A. Valtz, C. Coquelet, R. Privat, and J.-N. Jaubert, "Experimental measurements and correlation of vapor-liquid equilibrium and critical data for the $\mathrm{CO} 2+\mathrm{R} 1234 \mathrm{yf}$ and $\mathrm{CO} 2+$ R1234ze(E) binary mixtures," International Journal of Refrigeration, vol. 47, pp. 141-152, Nov. 2014.

[46] G. Di Nicola, F. Polonara, G. Santori, and R. Stryjek, "Isochoric PVTx Measurements for the Carbon Dioxide + 1,1-Difluoroethane Binary System," J. Chem. Eng. Data, vol. 52, no. 4, pp. 1258-1261, Jul. 2007. 
[47] G. Di Nicola, M. Pacetti, F. Polonara, and R. Stryjek, "Isochoric Measurements for CO2 + R125 and CO2 + R32 Binary Systems," J. Chem. Eng. Data, vol. 47, no. 5, pp. 1145-1153, Sep. 2002.

[48] G. Di Nicola, F. Polonara, R. Ricci, and R. Stryjek, "PVTx Measurements for the R116 + CO2 and R41 + CO2 Systems. New Isochoric Apparatus," J. Chem. Eng. Data, vol. 50, no. 2, pp. 312-318, Mar. 2005.

[49] F. F. Czubinski, C. J. Noriega Sanchez, A. K. da Silva, M. A. Marcelino Neto, and J. R. Barbosa, "Phase Equilibrium and Liquid Viscosity of CO2 + n-Dodecane Mixtures between 283 and 353 K," Journal of Chemical \& Engineering Data, vol. 64, no. 8, pp. 3375-3384, 2019.

[50] F. F. Czubinski, C. J. N. Sanchez, A. K. da Silva, M. A. M. Neto, and J. R. Barbosa, "Phase equilibrium and liquid viscosity data for R-290/POE ISO 22 mixtures between 283 and $353 \mathrm{~K}$," International Journal of Refrigeration, vol. 114, pp. 79-87, Jun. 2020. 